\title{
Práticas pedagógicas de ensinar-aprender: por entre resistências e resignações
}

\author{
Maria Amélia Santoro Franco'
}

\begin{abstract}
Resumo
0 presente artigo tem como pressuposto a consideração de que as práticas pedagógicas se configuram na mediação com o outro, ou com os outros, e é esse outro que oferece às práticas seu espaço de possibilidade. Contraditoriamente, observa-se que as práticas podem funcionar como espaço de resistência e de reverberação de múltiplas dominações; portanto, como um espaço eivado de contradições. Os dados empíricos que permitiram a construção desses pressupostos decorrem de uma pesquisa-ação pedagógica (FRANC0, 2012) realizada com docentes de ensino fundamental. A análise desses dados, realizada por meio da hermenêutica crítica, permite a discussão de três objetivos: a) analisar a abrangência e as possibilidades da prática pedagógica como espaço de contradição e de resistência; b) compreender a importância da pedagogia como ciência que pode esclarecer e indicar reflexões para as resistências que, inexoravelmente, impõem-se às práticas; e c) identificar as possibilidades da pesquisa-ação pedagógica como instrumento de mediação das contradições e como dispositivo formativo na negociação de sentidos que emergem das práxis. Conclui compreendendo que, na tensão primordial inerente ao processo de ensinar-aprender, convivem resistências e resignações; aprendizagens e possibilidades. As práticas pedagógicas operam a partir do diálogo fecundo, crítico e reflexivo, que se estabelece entre os múltiplos sujeitos, entre intencionalidades e ações. A retirada dessa esfera de reflexão crítica e do diálogo entre intencionalidades e ações implica o empobrecimento do sentido da prática educativa. Reafırma-se que os princípios fundadores da pesquisa-ação pedagógica podem auxiliar na ressignificação de práticas escolares.
\end{abstract}

\section{Palavras-chave}

Práticas pedagógicas - Práticas educativas - Pedagogia Pesquisa-ação pedagógica. 


\section{Pedagogical practices of teaching-learning: amid resistances and resignations}

Maria Amélia Santoro Franco'

\begin{abstract}
This article presupposes that pedagogical practices are configured in the mediation with the other, or with others, and that the other offers practices his or her space of possibility. Paradoxically, practices can work as a space of resistance and reverberation of multiple dominations; therefore, as a space riddled with contradictions. The empirical data that allowed the construction of these assumptions result from pedagogical action research (FRANCO, 2012) conducted with primary education teachers. Performed by critical hermeneutics, data analysis allows the discussion of three objectives: a) to analyze the scope and possibilities of pedagogical practice as a space of contradiction and resistance; b) to understand the importance of pedagogy as science that can clarify and indicate reflections for the resistances that inexorably impose themselves on practice; and c) to identify the possibilities of pedagogical action research as an instrument of mediation of the contradictions and as a formative device in the negotiation of meanings that emerge from praxes. It concludes that, in the primordial tension inherent in the process of teaching-learning, resistances and resignations, as well as learning and possibilities coexist. Pedagogical practices operate from the fertile, critical and reflective dialogue established between multiple subjects, and between intentionalities and actions. The removal of this sphere of critical reflection and dialogue between intentionalities and actions leads to the impoverishment of the sense of educational practice. This article reaffirms that the founding principles of pedagogical action research can assist in resignifying school practices.
\end{abstract}

\section{Keywords}

Pedagogical practices - Educational practices - Pedagogy Pedagogical action research. 
Resistência é um conceito originariamente ético, e

não estético.

O seu sentido mais profundo apela para a força da vontade que resiste a outra força, exterior ao sujeito.

Resistir é opor a força própria à força alheia. 0 cognato próximo é in/sistir; o antônimo familiar é de/sistir.

Alfredo Bos

\section{Introdução}

A questão investigativa que trago neste artigo foi desencadeada nas discussões que se seguiram a uma palestra que apresentei no VII Seminário Internacional Redes, ocorrida em junho de 2013, na Universidade Estadual do Rio de Janeiro (UERJ). Em uma mesa com Jean Houssaye, professor da Université de Rouen, discutimos as possibilidades da aula expositiva na atualidade. Comecei apresentando alguns mitos que rondam a significação das práticas de ensinar-aprender. A identificação e análise desses mitos eu os tenho realizado com professores que partilham comigo pesquisas, junto ao observatório da prática docente, projeto que desenvolvo junto ao Conselho Nacional de Desenvolvimento Científico e Tecnológico (CNPq), desde 2007 (FRANCO, 2010; 2013), na perspectiva metodológica do que venho denominando pesquisa-ação pedagógica.

Ao rever os mitos para discuti-los nessa mesa redonda, veio-me a questão de que as práticas pedagógicas se configuram na mediação com o outro, ou com os outros, e é esse outro que oferece às práticas seu espaço de possibilidade. Portanto, as práticas podem funcionar como espaço de resistência e também de reverberação de múltiplas dominações. Trata-se de um espaço eivado de contradições. As práticas pedagógicas revelam o outro da relação educativa. 0 outro pode/deve, muitas vezes, resistir e não entrar no jogo proposto pela prática pedagógica. No entanto, a compreensão/enfrentamento dessas resistências configuram à pedagogia um papel fundamental. Por entre resistências, desistências e insistências, a pedagogia se faz prática e habita entre nós.
Quero, neste texto, discutir a abrangência e as possibilidades da prática pedagógica como espaço de contradição, da pesquisa-ação pedagógica como instrumento de mediação das contradições e da pedagogia como ciência que pode iluminar a compreensão da inexorabilidade dessas resistências frente às práticas, realçando seu papel na negociação de sentidos que emergem das práxis e que permitem sua reconfıguração. Coloco como questão central para este artigo a que me foi posta pela plateia: se a pedagogia é sempre uma intervenção nas práticas educativas, qual é o papel das práticas pedagógicas frente às resistências postas pelos sujeitos da prática?

\section{Pedagogia como práxis: a esfera do imponderável}

A pedagogia e suas práticas são da ordem da práxis; assim, ocorrem em meio a processos que estruturam a vida e a existência. A pedagogia caminha por entre culturas, subjetividades, sujeitos e práticas. Caminha pela escola, mas a antecede, acompanha-a e caminha além. A didática possui uma abrangência menor, mais focada nos processos escolares dentro das salas de aula. A pedagogia coloca intencionalidades, projetos alargados; a didática compromete-se a dar conta daquilo que se instituiu chamar de saberes escolares. A lógica da didática é a lógica da produção da aprendizagem (nos alunos), a partir de processos de ensino previamente planejados. A prática da didática é, portanto, uma prática pedagógica. A prática pedagógica inclui a didática e a transcende.

Muitas questões logo se colocam: posso planejar o ensino-aprendizagem ou apenas será possível planejar atividades que talvez conduzam à aprendizagem? Trabalha a didática na perspectiva do talvez? Será esse talvez o componente que carrega a didática de certa imponderabilidade? Posso controlar a aprendizagem que decorre do ensino? Ou as aprendizagens são caminhos construídos pelos sujeitos a partir de suas interpretações 
e vivências nas diferentes esferas de vida? 0 professor concretiza sua ação pedagógica ao dar aula ou a concretiza quando consegue ensinar alguma coisa a alguém? 0 aluno precisa aprender. Aprender o que o professor deseja ou aprender o que o momento lhe permite aprender? Posso/devo como professor controlar o que o aluno aprende?

Planeja-se o ensino na intencionalidade da aprendizagem futura do aluno. No entanto, o grande desafıo da didática tem sido a impossibilidade de controle ou previsão da qualidade e da especificidade das aprendizagens que decorrem de determinadas situações de ensino.

0 planejamento do ensino, por mais eficiente que seja, não poderá controlar a imensidão de possibilidades das aprendizagens que cercam um aluno. Como saber o que o aluno aprendeu? Como planejar o próximo passo de sua aprendizagem? Precisamos de planejamento de ensino ou de acompanhamento crítico e dialógico dos processos formativos dos alunos?

A contradição sempre está posta nos processos educativos: o ensino só se concretiza nas aprendizagens que produz! E as aprendizagens, em seu sentido alargado e bem estudadas pelos pedagogos cognitivistas, decorrem de sinteses interpretativas realizadas nas relações dialéticas do sujeito com seu meio. Não são imediatas, não são previsíveis, ocorrem por interpretação do sujeito, dos sentidos criados, das circunstâncias atuais e antigas. Enfım, não há correlação direta entre ensino e aprendizagem. Quase que se pode dizer que as aprendizagens ocorrem sempre para além, ou para aquém do planejado; ocorrem nos caminhos tortuosos, lentos, dinâmicos das trajetórias dos sujeitos. Radicalizando essa posição, Deleuze (2006, p. 237) afırma que jamais será possível saber e controlar como alguém aprende.

Os processos de concretização das tentativas de ensinar-aprender ocorrem por meio das práticas pedagógicas. Essas são vivas, existenciais, por natureza, interativas e impactantes. As práticas pedagógicas são aquelas práticas que se organizam para concretizar determinadas expectativas educacionais. São práticas carregadas de intencionalidade e isso ocorre porque o próprio sentido de práxis configura-se através do estabelecimento de uma intencionalidade, que dirige e dá sentido à ação, solicitando uma intervenção planejada e científica sobre o objeto, com vistas à transformação da realidade social. Tais práticas, por mais planejadas que sejam, são imprevisíveis porque nelas "nem a teoria, nem a prática tem anterioridade, cada uma modifica e revisa continuamente a outra" (CARR, 1996, p. 101).

As aprendizagens ocorrem entre os múltiplos ensinos que estão presentes, inevitavelmente, nas vidas das pessoas e que competem ou potencializam o ensino escolar. Há sempre concomitâncias de ensino. Aí está o desafio da tarefa pedagógica hoje: tornar o ensino escolar tão desejável e vigoroso quanto outros ensinos que invadem a vida dos alunos.

Dessa forma, podemos perceber o perigo que ronda os processos de ensino quando este se torna excessivamente técnico, planejado e avaliado apenas em seus produtos finais. A educação se faz em processo, em diálogos, nas múltiplas contradições que são inexoráveis entre sujeitos e natureza, que mutuamente se transformam. Medir apenas resultados e produtos de aprendizagens como forma de avaliar o ensino pode se configurar como uma grande falácia!

A ação educativa verdadeira só pode ser vista como práxis que integra, conforme Kosik (1995), dois aspectos - o laborativo e o existencial - e se manifesta tanto na ação transformadora do homem, como na formação da subjetividade humana. Quando se deixa de considerar o lado existencial, a práxis se perde como significado e permite ser utilizada como manipulação. (FRANCO, 2001).

Considero que as relações entre professor, aluno, currículo e escola são relações que impõem uma convivência, tensional e contraditória, entre o sujeito que aprende e o professor que se 
organiza e prepara as condições para ensinar. 0 professor pode encontrar meios para viver a dissonância das resistências e resignações postas pelo aluno, quer atuando como desencadeador de processos de aprendizagem, quer como acompanhante das possibilidades múltiplas de retorno de sua ação.

Enfim, como a vida, o que decorre da ação de um bom ensino serão sempre situações imponderáveis! 0 importante é acompanhar, vigiar, recompor e readequar o planejado inicial. Essa dinâmica, que vai do desencadear nos alunos situações desafiadoras, intrigantes, exigentes, aos retornos que os alunos produzem, misturando vida, experiência atual e interpretações dos desafios postos, é a marca da identidade do processo ensino-aprendizagem, visto em sua complexidade e amplitude.

Considero que as práticas pedagógicas devam se estruturar como instâncias críticas das práticas educativas, na perspectiva de transformação coletiva dos sentidos e significados das aprendizagens.

0 professor, no exercício de sua prática docente, pode ou não se exercitar pedagogicamente. Ou seja, sua prática docente, para se transformar em prática pedagógica, requer, pelo menos, dois movimentos: o da reflexão crítica de sua prática e o da consciência das intencionalidades que presidem suas práticas. A consciência ingênua de seu trabalho (FREIRE, 1979) impede-o de caminhar nos meandros das contradições postas e, além disso, impossibilita sua formação na direção de um profissional crítico.

\section{Práticas pedagógicas: por entre} resistências e insistências

Tenho notado alguma dificuldade entre professores em perceber o sentido que costumo atribuir à prática pedagógica ou mesmo aos saberes pedagógicos. Percebo que há certa tendência de considerar como pedagógico apenas o roteiro didático de apresentação de aula, apenas o visível dos comportamentos utilizados pelo professor durante uma aula. Carr (1996) ajuda-nos a compreender essa questão quando diferencia o conceito de poiesis do conceito de práxis. Esse autor considera a poiesis como uma forma de saber fazer não reflexivo, ao contrário do conceito de práxis, que é eminentemente uma ação reflexiva. Assim, realça que a prática educativa não se fará inteligível, como forma de poiesis, cuja ação será regida por fins pré-fixados e governada por regras pré-determinadas. Para o autor, a prática educativa só adquirirá inteligibilidade "à medida que for regida por critérios éticos imanentes à mesma prática educativa” (CARR, 1996, p. 102), os quais, segundo ele, servem para distinguir uma boa prática de uma prática indiferente ou má. Eu utilizaria o termo para especificar que esses critérios servirão para distinguir uma prática pedagogicamente tecida de outra, apenas tecnologicamente tecida.

Portanto, uma aula só se torna uma prática pedagógica quando ela se organiza em torno: de intencionalidades, de práticas que dão sentido às intencionalidades; de reflexão contínua para avaliar se a intencionalidade está atingindo todos; de acertos contínuos de rota e de meios para se atingir os fins propostos pelas intencionalidades. Configura-se sempre como uma ação consciente e participativa.

Considero interessante especificar os princípios que organizam uma prática pedagógica:

a) As práticas pedagógicas organizam-se em torno de intencionalidades previamente estabelecidas e tais intencionalidades serão perseguidas ao longo do processo didático, de formas e meios variados.

$\mathrm{Na}$ práxis, a intencionalidade rege os processos. Para a filosofia marxista, a práxis é entendida como a relação dialética entre homem e natureza, na qual o homem, ao transformar a natureza com seu trabalho, transforma a si mesmo. Marx (1994) afirma, na oitava tese sobre Feuerbach: 
[...] que toda vida social é essencialmente prática. Todos os mistérios que dirigem a teoria para o misticismo encontram sua solução na práxis humana e na compreensão dessa práxis.

A compreensão dessa práxis é tarefa pedagógica. Kosik (1995, p. 222) realça que a práxis é a esfera do ser humano, portanto, não é uma atividade prática contraposta à teoria, mas práxis "é determinação da existência como elaboração da realidade”. Uma intervenção pedagógica como instrumento de emancipação considera a práxis como uma forma de ação reflexiva que pode transformar a teoria que a determina, bem como transformar a prática que a concretiza.

Uma característica importante da práxis, analisada por Vásquez (1968, p. 240), é o caráter finalista da práxis, antecipador dos resultados que se quer atingir, e esse mesmo aspecto é enfatizado por Kosik (1995, p. 221) ao afırmar que na práxis a "realidade humano-social se desvenda como o oposto ao ser dado, isto é, como formadora e ao mesmo tempo forma específica do ser humano". Talvez seja por isso que o autor diz que a práxis tanto é objetivação do homem e domínio da natureza, como realização da liberdade humana.

Realce-se, portanto, que a práxis permite ao homem conformar suas condições de existência, transcendê-las e reorganizá-las. Só a dialética do próprio movimento transforma o futuro e essa dialética carrega a essencialidade do ato educativo: intencionalidade coletivamente organizada e em contínuo ajuste de caminhos e práticas. Talvez o termo mais adequado seja o da insistência. 0 professor não pode desistir do aluno. Há que insistir, ouvir, refazer, fazer de outro jeito, acompanhar a lógica do aluno, descobrir e compreender as relações que ele estabelece com o saber, mudar o enfoque didático, as abordagens de interação e os caminhos do diálogo.

b) As práticas pedagógicas caminham por entre resistências e desistências, em uma perspectiva dialética, pulsional, totalizante.
Quando o professor chega a um momento de produzir um ensino em sala de aula, muitas circunstâncias estão presentes: desejos; formação; conhecimento do conteúdo; conhecimento das técnicas didáticas; ambiente institucional; práticas de gestão; clima e perspectiva da equipe pedagógica; organização espaço-temporal das atividades; infraestrutura; equipamentos; quantidade de alunos; organização e interesse dos alunos; conhecimentos prévios, vivências, experiências anteriores; enfım, muitas variáveis.

Muitas dessas variáveis induzem a uma boa interação, a um bom interesse e diálogo entre as variáveis do processo-aluno, professor e conhecimento -, vistas na perspectiva deHoussaye (1995) como o triângulo pedagógico. Como atua o professor? Como aproveita os condicionantes favoráveis e anula os que não ajudarão na hora? Tudo exige do professor reflexão e ação. Tudo exige dele um comportamento compromissado e atuante. Tudo nele precisa de empoderamento. As práticas impõem posicionamento, atitude, força e decisão. Fundamentalmente, é exigido do professor trabalhar com as contradições. Como está o professor preparado para tal? A ausência da reflexão, o tecnicismo exagerado, as desconsiderações aos processos de contradição e de diálogo podem resultar em espaços de engessamento das capacidades de discutir/ propor/mediar concepções didáticas. A ausência do espaço pedagógico pode significar o crescimento de espaço de dificuldade ao diálogo.

Sabe-se que o diálogo só ocorre na práxis (FREIRE, 1979), a qual requer e promove a ultrapassagem e superação da consciência ingênua em consciência crítica. Assim, concordando com Freire (1979, p. 25), posso acreditar que a superação da contradição “é o parto que traz ao mundo este homem novo, não mais opressor, não mais oprimido, mas o homem libertando-se." Talvez a prática pedagógica, absorvendo, compreendendo e transformando as resistências e resignações, possa mediar a superação dessas, em processos de emancipação e aprendizagens. Tenho sempre 
me utilizado das reflexões de Imbert (2003) quando ele realça a distinção entre prática e práxis, ao reafırmar o que venho enaltecendo neste texto e atentando para a autonomia e para a perspectiva emancipatória, inerente ao sentido de práxis:

Distinguir práxis e prática permite uma demarcação das características do empreendimento pedagógico. Há, ou não, lugar na escola para uma práxis? Ou será que, na maioria das vezes, são, sobretudo, simples práticas que nela se desenvolvem, ou seja, um fazer que ocupa o tempo e o espaço, visa a um efeito, produz um objeto (aprendizagem, saberes) e um sujeito-objeto (um escolar que recebe esse saber e sofre essas aprendizagens), mas que em nenhum momento é portador de autonomia. (IMBERT, 2003, p. 15).

Portanto, só a ação docente, realizada como prática social, pode produzir saberes, saberes disciplinares, saberes referentes a conteúdos e sua abrangência social, ou mesmo saberes didáticos, referentes às diferentes formas de gestão de conteúdos, de dinâmicas da aprendizagem, de valores e projetos de ensino. Tenho realçado o sentido de saberes pedagógicos como sendo aqueles que permitem ao professor a leitura e a compreensão das práticas. Ao mesmo tempo, permitem ao sujeito colocar-se em condição de dialogar com as circunstâncias dessa prática, dando-lhe possibilidade de perceber e auscultar as contradições. Assim, ele pode articular teoria e prática. É possível, portanto, falar em saberes pedagógicos como sendo saberes que possibilitam aos sujeitos construir conhecimentos sobre a condução, a criação e a transformação dessas mesmas práticas. 0 saber pedagógico só pode se constituir a partir do próprio sujeito, que deverá ser formado como alguém capaz de construção e de mobilização de saberes.

A grande dificuldade em relação à formação de professores é que, se quisermos ter bons professores, teremos de formá-los como sujeitos capazes de produzir conhecimentos, ações e saberes sobre a prática. Não basta fazer uma aula; é preciso saber porque tal aula se desenvolveu daquele jeito e naquelas condições: ou seja, é preciso a compreensão e leitura da práxis.

Quando um professor é formado de modo não reflexivo, não dialógico, desconhecendo os mecanismos e movimentos da práxis, ele não saberá potencializar as circunstâncias que estão postas à prática. Ele desistirá e replicará fazeres. 0 sujeito professor precisa ser dialogante, crítico e reflexivo. Ter consciência das intencionalidades que presidem sua prática. Sintetizando com a afırmativa de Imbert (2003, p. 27): "o movimento em direção ao saber e à consciência do formador não é outro senão o movimento de apropriação de si mesmo".

c) As práticas pedagógicas trabalham com e na historicidade; implicam tomadas de decisões; de posições e se transformam pelas contradições.

Por que assim se fazem? Por que tais práticas não podem ser congeladas, reificadas e realizarem-se linearmente? Não podem porque são práticas que se exercem na interação de sujeitos, de práticas e de intencionalidades. À medida que o professor desconsiderar as especificidades dos processos pedagógicos e tratar a educação como produto e resultados, numa concepção ingênua da realidade, o pedagógico teima em não se instalar, porque, nesses processos em que se pasteurizam a vida e a existência, não há espaço para o imprevisível, para o emergente, para as interferências culturais, para o novo.

As práticas pedagógicas estruturam-se em mecanismos paralelos e divergentes de rupturas e conservação. À medida que diretrizes de políticas públicas consideram a prática pedagógica como mero exercício reprodutor de fazeres e ações externas aos sujeitos, essas se perdem e muitos se perguntam: por que não conseguimos mudar a prática? A prática não muda por decretos ou por imposições. A prática pode mudar quando 
houver o envolvimento crítico e reflexivo dos sujeitos da prática (FRANCO, 2006).

Sabe-se que a educação é uma prática social humana; é um processo histórico inconcluso, que emerge da dialética entre homem, mundo, história e circunstâncias. Sendo um processo histórico, a educação não poderá ser vivenciada por meio de práticas que desconsideram sua especificidade. Os sujeitos sempre têm resistências para lidar com imposições que não abrem espaço ao diálogo e à participação. Como nos alerta Freire (1983, p. 27):

0 conhecimento, pelo contrário, exige uma presença curiosa do sujeito face ao mundo. Requer sua ação transformadora sobre a realidade. Demanda uma busca constante. Implica em invenção e em reinvenção. Reclama a reflexão crítica de cada um sobre o ato mesmo de conhecer, pelo qual se reconhece conhecendo e, ao reconhecer-se assim, percebe o "como" de seu conhecer e os condicionamentos a que está submetido seu ato.

Sabe-se que a educação, como prática social histórica, transforma-se pela ação dos homens e produz transformações nos que dela participam. Dessa forma, é fundamental que o professor esteja sensibilizado em reconhecer que, ao lado das características observáveis do fenômeno, existe um processo de transformação subjetiva, que não apenas modifica as representações dos envolvidos, mas produz uma ressignificação na interpretação do fenômeno vivido, o que produzirá uma reorientação nas ações futuras. Assim, é importante que o professor compreenda as transformações dos alunos, das práticas, das circunstâncias em processo.

Realço a necessidade da consideração do caráter dialético das práticas pedagógicas, no sentido de considerar que a subjetividade constrói a realidade e essa se modifica por meio da interpretação coletiva. A educação permite sempre uma polissemia em sua função semiótica, ou seja, nunca existe uma relação direta entre o significante observável e o significado. Assim, as práticas pedagógicas serão, a cada momento, expressão do momento e das circunstâncias atuais. Serão sínteses provisórias que se organizam no processo de ensino. As situações de educação estão sempre sujeitas a circunstâncias imprevistas, não planejadas e, dessa forma, os imprevistos acabam redirecionando o processo e, muitas vezes, permitindo uma reconfıguração da situação educativa.

Portanto, o trabalho pedagógico requer espaço de ação sobre e de análise do não planejado, do imprevisto, da desordem aparente. Isso deve pressupor a ação coletiva, dialógica e emancipatória entre alunos e professores. Toda ação educativa tem em seu fazer uma carga de intencionalidade que integra e organiza sua práxis, confluindo, de maneira dinâmica e histórica, tanto as características do contexto sociocultural como as necessidades e possibilidades do momento as concepções teóricas e a consciência das ações cotidianas, em um amalgamar provisório que não permite que uma parte seja analisada sem referência ao todo, nem que este seja visto como síntese provisória das circunstâncias parciais do momento.

É por isso que reafirmo que práticas pedagógicas requerem do professor adentrar na dinâmica e significado da práxis, de forma a poder compreender as teorias implícitas que permeiam as ações do coletivo de alunos. A prática precisa ser tecida e construída a cada momento e a cada circunstância, pois, como Certeau (1994), acredito que a vida sempre nos escapa e se inventa de mil maneiras não autorizadas, com movimentos táticos e estratégicos.

As práticas pedagógicas incluem desde planejar e sistematizar a dinâmica dos processos de aprendizagem até caminhar no meio de processos que ocorrem para além dela, de forma a garantir o ensino de conteúdos e de atividades que são considerados fundamentais para aquele estágio de formação do aluno, e, através desse processo, criar nos alunos mecanismos de mobilização de seus saberes anteriores construídos em outros espaços educativos. 
0 professor, em sua prática pedagogicamente estruturada, deverá saber recolher como ingredientes do ensino essas aprendizagens de outras fontes, de outros mundos, de outras lógicas, para incorporar na qualidade de seu processo de ensino e na ampliação daquilo que se considera necessário para o momento pedagógico do aluno.

\section{Pesquisa-ação: compreender e} transformar as práticas

Tenho utilizado a pesquisa-ação pedagógica (FRANCO, 2010, 2011, 2012b, 2013) como instrumento de disponibilizar aos docentes dispositivos pedagógicos que permitem facilitar a compreensão de suas práticas. Ao fazer isso, tenho constatado que a compreensão da dinâmica e funcionamento das práticas potencializa sua transformação.

Sabe-se que os saberes docentes compõemse de uma multiplicidade de dimensões, entre as quais se evidenciam: os saberes da formação profissional; os saberes disciplinares; os saberes curriculares; e os saberes da experiência. No entanto, há que se considerar que tais saberes se organizam, se entrecruzam, se mobilizam, se reformulam pela capacidade do sujeito interrogante, dialogante, crítico e criativo. Nessa direção, pode-se dizer que o sujeito, para integrar e potencializar tais saberes em sua prática profissional, precisa constituir-se em um sujeito empoderado, ou seja, com capacidade de diálogo e contato consigo próprio, com disponibilidade de aproveitar-se da crítica e do coletivo para recompor e atualizar tais saberes.

Investigações com pesquisa-ação pedagógica (FRANCO, 2012a) fundamentada na abordagem crítica parecem contribuir com a perspectiva de oferecer aos docentes mecanismos de articulação das práticas com as intencionalidades coletivas. Isso ocorre, primeiramente, porque trabalha sempre com o pressuposto da autoria individual, da participação dos sujeitos em todo processo de construção dos conhecimentos.
Em segundo lugar, porque possibilita sistematizar os processos críticos e reflexivos, dando-lhes uma dimensão científica, para além do bom senso e da espontaneidade. Para tanto, organiza as reflexões dos participantes em torno dos condicionantes ideológicos, políticos e econômicos, "desvelando as forças tácitas que constroem a consciência no nível da vida cotidiana" (KINCHELOE, 1996, p. 219).

Em terceiro lugar, porque induz os participantes a uma reconceitualização crítica de suas práticas, de suas crenças e de suas concepções na direção da construção de práticas mais adequadas a seus objetivos atuais.

Por último, a pesquisa-ação crítica busca substituir a colonização cognitiva e emocional dos professores por uma pedagogia da participação, que vai procurando aproximar o sujeito à sua consciência, seu saber de seu fazer, sua intencionalidade de sua prática - encaminhando o sujeito a substituir, na linguagem de Paulo Freire, a consciência ingênua por caminhos de uma consciência crítica.

Um dos grandes desafios da formação de professores, portanto, tem sido a articulação entre teoria e prática, considerando-se a insuficiência da perspectiva técnica, que separa e fragmenta a realidade da práxis, valorizando apenas a tecnologia da prática, seu observável, seu aparente, o visível. Nesse sentido, reconheço, conforme Grundy (1982, p. 358), que é somente mediante a crítica, em especial a reflexão crítica, que será possível estabelecer as mediações entre teoria e prática.

A reflexão pautada na crítica esclarece os condicionantes que organizaram as práticas anteriores, referendando ou refutando concepções que não estão mais presentes nos contextos atuais. Diz Grundy (1982) que, quando uma pessoa reflete a respeito de uma teoria à luz da práxis ou do julgamento prático, o conhecimento que emerge desse processo é um conhecimento pessoal ou tácito, que é possibilitado pela interação crítica entre teoria, esclarecimento e ação.

0 professor em processo de formação, dentro da perspectiva de uma epistemologia 
crítica da prática, enriquece-se quando percebe como construir, rever, criticar e ressignificar, em processo, tais conhecimentos. A pesquisa-ação funciona como um instrumento que o coloca em contato com suas construções cognitivas, suas concepções de prática, suas representações culturais.

A pesquisa-ação trabalha na/com a práxis. Para isso, utiliza-se da imbricação de dois eixos fundamentais: o eixo da ação, que parte de uma ação individual para uma ação estruturada coletivamente; e o eixo da significação da ação, que parte de uma concepção individual, pautada em bom senso, e chega ao esclarecimento crítico ideológico. Mediando os dois eixos, encontra-se a reflexão coletiva e emancipatória.

A pesquisa-ação crítica contempla a articulação desses eixos por meio do trabalho dialético das espirais cíclicas (LEWIN, 1946) em torno do processo reflexivo. Assim, posso explicitar:

a) Eixo da ação: a pesquisa-ação crítica organiza-se em torno da abertura do individual ao coletivo, permeando essa relação com os processos de socialização e crítica coletiva. Com o movimento de reflexão cíclica desencadeando-se pela prática da pesquisa, o fazer individual socializa-se, compondo-se com o coletivo, incorporando os anseios que vão sendo esclarecidos na práxis investigativa, coletivamente construída;

b) Eixo da significação ${ }^{1}$ : Como os sujeitos concebem as razões de suas ações? Como identificam as teorias que as fundamentam? Normalmente os docentes atribuem às suas ações práticas um significado intuitivamente elaborado, fruto de bom senso, das teorias não explícitas. Quando mergulham em processos de pesquisa-ação, eles vão sendo interpelados pelo grupo, entram em processos de dissonância cognitiva e buscam no coletivo novas formas de perceber o mundo, de analisar os condicionantes ideológicos de sua prática.

1- Há autores que utilizam o termo: eixo de representação. Eu mesma já o utilizei (FRANCO, 2005). No entanto, considero que o conceito aproxima-se mais do termo significação. Considero que há uma interpretação partilhada da ação e essa interpretação condiz mais com o sentido de atribuir significados (FRANCO, 2012a).
Nesse mergulho, com o processo de práxis investigativa, os discursos que fundamentam sua prática vão sendo substituídos não por outros discursos, mas por uma nova maneira de perceber o mundo, que implica reconstrução da ação, o que normalmente coloca sob suspeita discursos anteriores. Ocorre um processo gradativo de desmistificação de suas convicções anteriores. A pesquisa-ação, por congregar a concomitância de pesquisa com ação, cria uma reciprocidade entre ações e discursos, entre pensar e agir, entre saberes e práticas. (FRANCO; LISITA, 2004).

Esses dois eixos são bem visualizados nos trabalhos de Morin (1992), em que o autor, ao descrever os modos de funcionamento da pesquisa-ação integral, realça que a "pesquisa-ação integral visa a uma mudança pela transformação recíproca da ação e do discurso" (MORIM, 1992, p. 21), isto é, de uma ação individual em uma prática coletiva mais pertinente e investigativa e de um discurso que vai aos poucos se transformando em um diálogo esclarecido e engajado.

A mudança dessas duas esferas relativas à ação e às suas formas de significação implica propriamente um processo formativo do sujeito e das condições existenciais de sua ação. É um trabalho eminentemente pedagógico e, nessas condições, político.

Nessa direção, Charlot (2002, p. 94) pode ajudar a referendar o papel da pesquisa-ação como integradora da teoria com a prática. 0 autor diz que não acredita que haja problema no diálogo da teoria com a prática. Porém, o que existe é um problema de diálogo entre dois tipos de teoria: uma teoria enraizada nas práticas e uma teoria que está se desenvolvendo na área da pesquisa e das próprias ideias entre os pesquisadores. Ele ajuda-nos a refletir em duas direções: a primeira sinalizando que, muitas vezes, a própria pesquisa, distante dos sujeitos da prática, elabora teorias que pouco têm a ver com a realidade da prática desempenhada pelos docentes; já a segunda induz-nos a refletir e reafirmar que os docentes possuem uma teoria que fundamenta suas práticas. 
Quando os professores participam de processos de pesquisa-ação, eles têm oportunidade de compreender a origem histórica de suas teorias e, com base nessa compreensão, conseguem propor e operar rupturas (cognitivas, emocionais) nas convicções das concepções que fundamentam suas práticas. É o que confirmam pesquisas desenvolvidas nessa perspectiva, tais como a de Franco (2013), cujos resultados referendam mudanças nas concepções pessoais e profissionais dos participantes.

Tenho investigado (FRANCO, 2012b) que a pesquisa-ação crítica permite a articulação entre os saberes científicos e os saberes práticos, fazendo emergir novos conhecimentos a respeito da realidade educativa.

Um dos pressupostos fundamentais de qualquer forma de pesquisa-ação é a convicção de que a pesquisa e a ação podem e devem caminhar juntas. Caminhar juntas não significa apenas uma concomitância temporal, mas, essencialmente, uma articulação dialética desses dois aspectos: o fazer reflexivo e o pesquisar; o fazer pesquisando e o pesquisar fazendo. $\mathrm{Na}$ pesquisa crítica, é fundamental que o fazer coletivo signifıque também a construção de movimentos intersubjetivos, interdialogais, intercomunicantes. Esses movimentos irão construindo um universo de significações coletivas organizado pelas mediações entre as experiências e os saberes individuais, formando uma rede de coformadores e gerando processos de autoformação continuada.

Franco (2003, p. 99) considera que todos os envolvidos na prática reflexiva precisam constituir-se em investigadores no contexto da práxis e, nesse sentido, poderão desenvolver saberes para sua emancipação como sujeitos. Esses saberes referem-se tanto a predisposições para participar de um processo de pesquisa, como à disponibilidade para se construir como pesquisador de sua prática ou, ainda, à possibilidade de se transformar em um sujeito produtor de conhecimento.

Para transformar uma ação pedagógica em práticas colaborativas, considero fundamental que pesquisadores e professores se engajem em processos mútuos de aprender-ensinar, de estranhar-compreender. É preciso superar a perspectiva de serem os docentes vistos apenas como objetos de estudo; é preciso tempo e espaço para que pesquisadores e sujeitos da prática sejam, ao mesmo tempo, participantes e protagonistas. Esse é um dos aspectos importantes do processo de conscientização tão bem explicado por Freire (1983). Trata-se de transformar a consciência ingênua em consciência crítica, de superar e transcender o senso comum; de produzir novas relações com o saber da docência.

É importante realçar: se quero a participação de todos, preciso organizar algum dispositivo para funcionar como estruturante de um universo comum de conhecimentos, conforme sempre nos alertou Paulo Freire (1979).

Criar um universo cultural coletivo é uma tarefa fundamental do pesquisador em pesquisa-ação; no entanto, precisa fazê-lo na perspectiva de construção coletiva, de buscar participação, permitindo a contribuição de todos. Um alerta: isso é diferente de organizar textos ou aulas para aplicar nos participantes! É fundamental essa postura de buscar o outro, partilhar valores e agir de modo coerente com as expressões do grupo.

Essa triangulação praxiológica entre valores, teorias e práticas é um processo exigente que, contudo, tem fontes de inspiração muito ricas na herança pedagógica do século vinte. Uma dessas inspirações é exatamente a investigação-ação, pois ela tem um papel muito relevante na formação do profissional docente reflexivo. (OLIVEIRA-FORMOSINHO; KISHIMOTO; PINAZZA, 2007).

Há que se recordar, conforme Contreras (1994), que a autonomia docente não é uma qualidade presente individualmente em cada sujeito, mas um processo que vai, gradativamente, garantindo a assunção, por parte do professor, de sua responsabilidade social pela condução do ensino em situações complexas, historicamente construídas e ideologicamente comprometidas. Isso só pode ser feito com um sujeito que se sinta, se 
perceba como ator de sua história, um sujeito empoderado, habilitado ao exercício do poder que advém de sua práxis.

A questão que se coloca é: como os professores, em sua grande maioria formados dentro dos pressupostos de uma racionalidade técnica, saberão reconstruir a epistemologia que rege suas práticas e transformar-se em sujeitos críticos de uma nova concepção de prática?

Ainda mais, pergunto: como os professores, inseridos em um contexto social e político que desvaloriza cotidianamente sua profissão, imersos num modelo hegemônico de democracia representativa liberal (SANTOS, 2002, p. 46) que desconsidera o papel da mobilização social e da ação coletiva, podem romper com tais condicionantes e fazerem-se sujeitos históricos, compromissados com uma práxis política emancipatória?

Como ainda os professores, alijados historicamente do papel de participante ativo e inseridos em sua maioria em processos de pauperização da profissão, podem encontrar forças e caminhos para constituírem-se como atores sociais, críticos e comprometidos com uma nova concepção de vida e mundo?

Suojanem (1999) tem um trabalho denominado A pesquisa-ação como estratégia para o empoderamento, no qual analisa que o exercício criativo e transformador de uma prática profissional só pode ser exercido pelos sujeitos que têm o sentimento de controle de sua vida e de suas decisões, o que lhes dá a capacidade de sentirem-se encorajados para mudar, rever, transformar. Empoderar, para a autora, é um ato de construção de capacidades, de desenvolvimento pessoal e coletivo, de apreensão, de crescente poder de conhecimento e controle, que vai se incorporando por meio do exercício da cooperação, do compartilhamento de saberes e do trabalho coletivo.

A autora realça que o empoderamento significa comprometer-se com os objetivos comuns, assumindo riscos e demonstrando iniciativa e criatividade, o que deve implicar uma direção ética, advinda do compromisso social coletivamente assumido. As práticas pedagógicas podem caminhar na direção da domesticação ou da emancipação. A consciência crítica, a autonomia, o empoderamento dos docentes, a tessitura coletiva das intencionalidades fará toda diferença no rumo dessas práticas.

\section{Considerações, decorrências e perspectivas}

A resistência estabelece-se naturalmente nas práticas pedagógicas, porque as lógicas de ensinar e de aprender não são lógicas lineares, nem lógicas paralelas. São, antes de tudo, lógicas que se embatem, que se contradizem e que se fundem em alguns momentos. 0 ensino implica: o planejamento das metas; a organização dos conteúdos de aprendizagem; os recortes daquele que ensina; a posição social e acadêmica do professor que supostamente sabe e do aluno que está ali para aprender com o professor. Já a aprendizagem implica especialmente o envolvimento, a adesão, a participação, a vontade e o desejo de aprender.

$\mathrm{Na}$ maioria das vezes, o professor quer ensinar e o aluno quer aprender; mas nem sempre entram em acordo. 0 aluno, muitas vezes, não aprende aquilo que o professor quer ensinar, mas aquilo que a vida e suas experiências disponibilizam. 0 professor quer ter a certeza de que o aluno aprendeu o saber ensinado; mas, muitas vezes, o aluno aprendeu outras coisas do saber ensinado. Como disse, não há uma correlação imediata entre ensinar e aprender. Sabe-se e muito enfatiza Charlot (2005) que, para aprender o aluno precisa envolver-se intelectual e emocionalmente, além de mobilizar sua atividade intelectual. Essa mobilização só ocorre quando o aluno dá sentido àquilo que querem ensinar-lhe. Freire (1979) realça com insistência, bem como Meirieu (1997), que, de alguma forma, precisamos da autorização da pessoa do aluno para entrar em sua lógica e assim configurar um processo de mútuo ensino-aprendizagem. 0 ensino sem sentido, imposto de fora para 
dentro e de cima para baixo não cria condições de aprendizagem.

As aprendizagens ocorrem na densidade das práticas pedagógicas, tecidas com o outro, no diálogo (FREIRE, 1979), na participação; na parceria, na compreensão das relações dos sujeitos com o saber (CHARLOT, 2005).

Nessa tensão primordial do processo de ensinar-aprender é que a pedagogia como ciência encontra seu espaço: será preciso compreender o que as práxis expressam e, conhecendo-as, adentrando em seu âmago, reconhecê-las, transformá-las, enriquecê-las com as vivências dos múltiplos sujeitos.

Assim, reafirmo que as práticas são da ordem da práxis, permeadas pela contradição, interpostas pelos movimentos de ruptura e conservação. Somente as práticas vivenciadas no coletivo e pedagogicamente estruturadas podem dar sentido aos processos de ensinar-aprender.
As práticas, para operarem, precisam do diálogo fecundo, crítico e reflexivo que se estabelece entre intencionalidades e ações. A retirada dessa esfera de reflexão, crítica e diálogo com as intencionalidades da educação implica o empobrecimento e, talvez, a anulação do sentido da prática educativa.

Aulas que se revestem apenas de reprodução de discursos áridos, de manipulação de textos prontos, de ausência de diálogo criativo e de reflexão em processo deixam de ser práticas pedagógicas, perdem o sentido e a razão de ser para os alunos.

Assim, proponho que os princípios fundadores da pesquisa-ação crítica, que tenho chamado de pesquisa-ação pedagógica (FRANCO, 2012), possam nortear e organizar os princípios didáticos das práticas escolares. $\mathrm{E}$ assim repito: por entre resistências, desistências e insistências a pedagogia se faz prática e habita entre nós.

\section{Referências}

CARR, Wilfred. Una teoría para la educación: hacia una investigación educativa crítica. Madrid: Morata, 1996.

CERTEAU, Michel de. A invenção do cotidiano: 1 - artes de fazer. Petrópolis: Vozes, 1994.

CHARLOT, Bernard: Formação de professores: a pesquisa e a política educacional. In: PIMENTA, Selma; GHEDIN, Evandro (Org.). Professor reflexivo no Brasil: gênese e crítica de um conceito. São Paulo: Cortez, 2002. p. 89-110.

CHARLOT, Bernard. Relação com o saber, formação de professores e globalização: questões para a educação hoje. Porto Alegre: Artmed, 2005.

CONTRERAS, José. La investigación en la acción. Cuadernos de Pedagogía, Barcelona, n. 224, p. 7-19, abr. 1994.

FRANCO, Maria Amélia Santoro. A pedagogia como ciência da educação. Campinas: Papirus, 2003.

FRANCO, Maria Amélia Santoro. A pedagogia como ciência da educação: entre praxis e epistemología, 2001. Tese (Doutorado em Educação) - Faculdade de Educação da Universidade de São Paulo, São Paulo, 2001.

FRANCO, Maria Amélia Santoro. A pedagogia da pesquisa-ação. Educação e Pesquisa, São Paulo, v. 31, n. 3, p. 483-502, dez. 2005.

FRANCO, Maria Amélia Santoro. Didática e pedagogia: da teoria do ensino à teoria da formação. In: FRANCO, Maria Amélia; PIMENTA, Selma Garrido. Didática: embates contemporâneos. São Paulo: Loyola, 2010. p. 75-100.

FRANCO, Maria Amélia Santoro. Entre a lógica da formação e a lógica das práticas: a mediação dos saberes pedagógicos. In: REUNIĨ̃ ANUAL DA ANPED, 29., 2006, Caxambu, Anais... Caxambu: Anped, 2006. Sessão especial. 1 CD Rom.

FRANCO, Maria Amélia Santoro. Observatório da prática docente: um espaço para compreensão/transformação da prática docente. São Paulo: [s. n.], 2007-2013. Projeto de pesquisa e relatório de pesquisa Capes/CNPq, 2007, 2011 e 2013. 
FRANCO, Maria Amélia Santoro. Pedagogia como ciência da educação. São Paulo: Cortez, 2008.

FRANCO, Maria Amélia Santoro. Pedagogia e prática docente. São Paulo: Cortez, 2012a.

FRANCO, Maria Amélia Santoro. Pesquisa-ação: balizando princípios metodológicos. In: STRECK, Danilo; SOBOTTKA, Emil A.; EGGERT, Edla (Org.). Conhecer e transformar: pesquisa-ação e pesquisa participante em diálogo internacional. Curitiba: CRV, 2013.

FRANCO, Maria Amélia Santoro. Práticas pedagógicas nas múltiplas redes sociais. In: LIBÂNEO, José Carlos; ALVES, Nilda. Doze temas da pedagogia: as contribuições do pensamento em currículo e em didática. v. 1. São Paulo: Cortez, 2012b. p. 169-189.

FRANCO, Maria Amélia Santoro; LISITA, Verbena. Action research: limits and possibilities in teacher education. British Education Index (BEI), Brotherton Library-University, p. 1-15, 2004.

FREIRE, Paulo. Ação cultural para a liberdade. Rio de Janeiro: Paz e Terra, 1979.

FREIRE, Paulo. Conscientização. São Paulo: Cortez, 1983.

GRUNDY, Shirley. Three modes of action research. London: The Falmer Press, 1982.

HOUSSAYE, Jean. Une illusion pédagogique? Cahiers Ppédagogiques, Paris, n. 334, p. 28-31, 1995.

IMBERT, Francis. Para uma práxis pedagógica. Brasília, DF: Plano, 2003.

KINCHELOE, Joe L. A formação do professor como compromisso político: mapeando o pós-moderno. Porto Alegre: Artes Médicas, 1997.

KOSIK, Karel. Dialética do concreto. 6. ed. Rio de Janeiro: Paz e Terra, 1995.

LEWIN, Kurt. Action Research and minority problems. Journal of Social Issues, New York, v, 2, p. 33-34, , 1946.

MARX, Karl; ENGELS, Friedrich. A ideologia alemã: teses sobre Feuerbach. São Paulo: Moraes, 1994.

MEIRIEU, Philippe. Le choix d'éduquer: éthique et pédagogie. Paris: ESF, 1997.

MORIN, André. Recherche-action intégrale et participation cooperative: méthodologie et etudes des cas. Laval: Agence d'Arc, 1992.

OLIVEIRA-FORMOSINHO, Júlia; KISHIMOTO, Tizuco; PINAZZA, Monica (Org.). Pedagogia(s) da infância: dialogando com 0 passado construindo o futuro. Porto Alegre: Artes Médicas. 2007.

SANTOS, Boaventura. Para ampliar o cânone democrático. In: SANTOS, Boaventura. Democratizar a democracia: os caminhos da democracia participativa. Rio de Janeiro: Civilização Brasileira, 2002.

SUOJANEN, Ulla. Action research - a strategy for empowerment. In: TURKKI, Kaija (Ed.). New approaches to the study of everyday life. p. II. Helsinki: Finland Publications 4, 1999.

VÁSQUEZ, Adolfo S. Filosofia da práxis. Rio de Janeiro: Paz e Terra, 1968.

Recebido em: 09.09.2014

Aprovado em: 25.03.2015

Maria Amélia do Rosário Santoro Franco é pedagoga, doutora em educação, pós-doutora em pedagogia. Pesquisadora 2 CNPq pela Universidade Católica de Santos. 